Case Report

\title{
Pneumocystis jirovecii Pneumonia in an Immunocompetent Japanese Man: A Case Report and Literature Review
}

\author{
Hiromi Ide $\left(\mathbb{D},{ }^{1}\right.$ Yoshikazu Yamaji, ${ }^{2}$ Kazunori Tobino, ${ }^{1}$ Masanobu Okahisa, ${ }^{1}$ \\ Kojin Murakami, ${ }^{1}$ Yuki Goto, ${ }^{1}$ Takuto Sueyasu, ${ }^{1}$ Saori Nishizawa, ${ }^{1}$ Kohei Yoshimine, ${ }^{1}$ \\ Miyuki Munechika $\mathbb{D}^{1},{ }^{1}$ Masafumi Oya, ${ }^{3}$ and Yuka Hiraki ${ }^{3}$ \\ ${ }^{1}$ Department of Respiratory Medicine, Iizuka Hospital, Japan \\ ${ }^{2}$ Department of Respiratory Medicine and Infectious Disease, Graduate School of Medicine, Yamaguchi University, Japan \\ ${ }^{3}$ Department of Pathology, Iizuka Hospital, Japan \\ Correspondence should be addressed to Hiromi Ide; ghiromix7@gmail.com
}

Received 4 January 2019; Accepted 20 February 2019; Published 7 March 2019

Academic Editor: Akif Turna

Copyright (C) 2019 Hiromi Ide et al. This is an open access article distributed under the Creative Commons Attribution License, which permits unrestricted use, distribution, and reproduction in any medium, provided the original work is properly cited.

\begin{abstract}
We herein report the case of a 37-year-old immunocompetent man who died from Pneumocystis jirovecii pneumonia (PCP). He was initially treated for an acute exacerbation of interstitial pneumonia; however, the elevation of the patient's serum (1-3) $\beta$-D glucan (BG) level suggested the possibility of PCP and sulfamethoxazole trimethoprim was added. A postmortem pathological examination and retrospective Grocott's methenamine silver (GMS) staining of the bronchoalveolar lavage fluid (BALF), which was obtained on the day of admission, revealed PCP. The present case suggests that it is essential to perform a BG assay and GMS staining of BALF specimens when patients show diffuse ground-glass opacity on chest computed tomography, regardless of their immune status.
\end{abstract}

\section{Introduction}

Pneumocystis jirovecii pneumonia (PCP) is a common opportunistic infection in patients with acquired immune deficiency syndrome (AIDS) [1]. In patients with human immunodeficiency virus (HIV), a low CD4+ lymphocyte count $(<200$ cells $/ \mu \mathrm{L})$ is a risk factor for the development of PCP; underlying malignancies, organ transplantation and immunosuppressive medications are other risk factors. PCP in patients without any of these risk factors is extremely rare [2]. We herein report a case of PCP in an immunocompetent patient.

\section{Case Presentation}

A 37-year-old Japanese man presented to our hospital with a nonproductive cough of two weeks in duration. He did not have fever or dyspnea. He had a history of right hemiparesis, intellectual disability with pica, and symptomatic epilepsy caused by intracerebral hemorrhage, which occurred at two years of age. He had never smoked or consumed alcoholic beverages.

His initial vital signs were as follows: blood pressure, 105/55 mm Hg; pulse rate, 70 beats/minute; respiratory rate, 18 breaths/min; $\mathrm{SpO}_{2}, 93 \%$ in room air; body temperature, $36.5^{\circ} \mathrm{C}$. There was no lymphadenopathy. Auscultation revealed no chest rales. A cardiovascular examination was normal, and no murmurs, rubs, or gallops were detected. Abdominal and neurological examinations were unremarkable, and the patient had no rash or petechiae. A chest radiograph revealed bilateral diffuse infiltration (Figure 1). Chest computed tomography $(\mathrm{CT})$ revealed bilateral airspace consolidation and ground-glass opacity (Figure 2).

The patient's laboratory test values were as follows: hemoglobin, $14.9 \mathrm{~g} / \mathrm{dl}$; white blood cell count, $8,850 / \mathrm{mm}^{3}$ with a left shift; platelets, $329,000 / \mathrm{mm}^{3}$; serum aspartate aminotransferase $29 \mathrm{U} / \mathrm{L}$ (normal, 0-35 U/l); serum alanine aminotransferase, $31 \mathrm{U} / \mathrm{L}$ (normal, 0-35 U/l); serum lactate dehydrogenase, $425 \mathrm{U} / \mathrm{L}$ (normal, 119-229 U/l); serum total protein, $5.3 \mathrm{~g} / \mathrm{dl}$ (normal, $6.5-8 \mathrm{~g} / \mathrm{dl}$ ); serum albumin, 2.1 


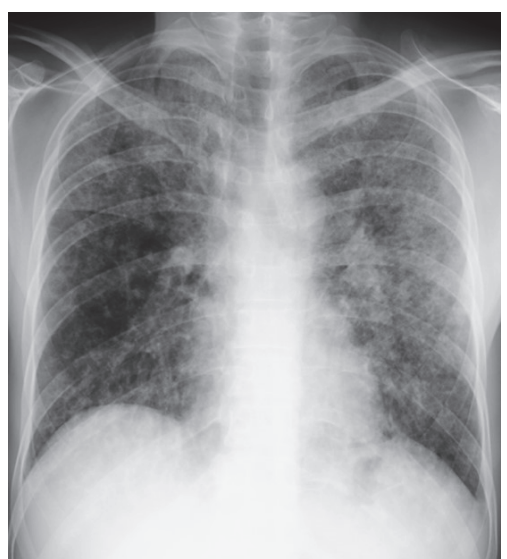

FIGURE 1: A chest radiograph obtained on the day of admission showed bilateral diffuse alveolo-interstitial infiltration, particularly in the left lung.

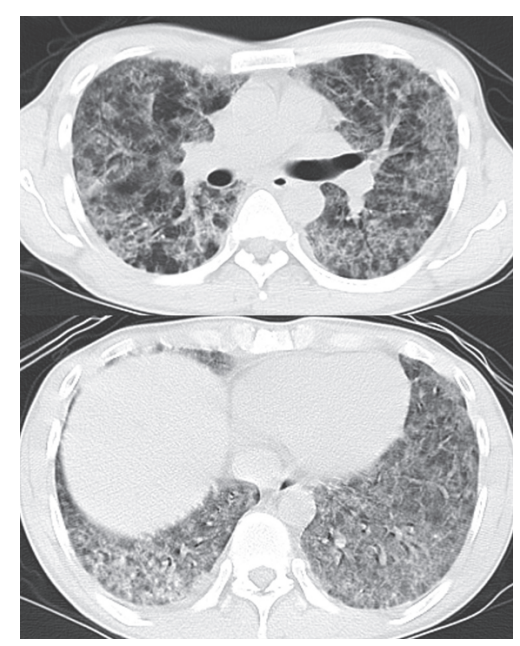

FIGURE 2: Chest computed tomography revealed bilateral airspace consolidation and ground-glass opacity.

g/dl (normal, 4-5 g/dl); serum C-reactive protein, $9.18 \mathrm{mg} / \mathrm{dl}$ (normal, < $0.2 \mathrm{mg} / \mathrm{dl}$ ); serum KL-6, $2940 \mathrm{U} / \mathrm{ml}$ (normal, < $500 \mathrm{U} / \mathrm{ml}$ ); serum surfactant protein $\mathrm{D}, 173.0 \mathrm{ng} / \mathrm{ml}$ (normal, $<109.9 \mathrm{ng} / \mathrm{mL}$ ); and serum surfactant protein A, $115.0 \mathrm{ng} / \mathrm{ml}$ (normal, $<43.8 \mathrm{ng} / \mathrm{mL}$ ). The patient's serum was negative for rheumatoid factor and antinuclear antibodies. The serum levels of immunoglobulin M, G, and A were within the normal ranges. An electrocardiogram revealed normal findings. An examination of the patient's sputum showed no predominant pathogen and no acid-fast organisms were observed on staining. Two sets of blood cultures were prepared at the time of admission; however, they did not yield any organisms.

The patient underwent a fiberoptic bronchoscopic examination that revealed a normal endobronchial system, and combined bronchoalveolar lavage (BAL)/transbronchial biopsy (TBLB) was performed. BAL fluid (BALF) was obtained from the right middle lobe. The results of the BALF analysis were as follows: histiocytes, $87 \%$; neutrophils, $6 \%$; lymphocytes, 4\%; and eosinophils, 3\%. Routine cultures of bronchial the washings were negative. The TBLB sample from the right upper lobe revealed alveolar septal thickening due to chronic inflammation, as well as collagen-type fibrosis.

After these examinations, the patient was diagnosed with acute interstitial pneumonia, and intravenous levofloxacin (500 mg) was administered once daily with corticosteroid pulse therapy (methylprednisolone [1000 mg] for three days) followed by prednisolone ( $1 \mathrm{mg} / \mathrm{kg} /$ day $)$. On the 5 th day after the initiation of therapy, his respiratory condition worsened and noninvasive positive pressure ventilation was started. His interstitial pneumonia was thought to be getting worse, and cyclophosphamide (500 mg/body) was administered intravenously. On the same day, an additional examination revealed the elevation of the serum (1-3) $\beta$-D glucan (BG) level $(104.3 \mathrm{pg} / \mathrm{ml}$; normal, $<6.0 \mathrm{pg} / \mathrm{ml})$. He was therefore suspected to have fungal infection or PCP, and voriconazole (200 mg, every 12 hours) and sulfamethoxazole trimethoprim (1600 $\mathrm{mg}$ and $320 \mathrm{mg}$, respectively, every 8 hours) were started. An additional HIV antibody test was negative and the serum protein electrophoresis revealed normal findings. Despite the additional antifungal therapy, his respiratory status gradually worsened, and intravenous corticosteroid pulse therapy (methylprednisolone [1000 mg] for three days) and cyclophosphamide therapy (500 mg/body) were each administered a second time, on the 8th and 11th days, respectively, without improvement. The patient died due to respiratory failure on the 12th day.

A postmortem pathological examination of the lung tissue demonstrated that the alveolar spaces were filled with foamy amorphous material composed of abundant numbers of cystic forms of Pneumocystis jirovecii and cellular debris, as well as an inflammatory reaction with hyaline membranes (Figure 3). Retrospectively, Grocott's methenamine silver (GMS) staining of the BALF and TBLB samples obtained on the day of admission revealed a small amount of the cystic form of Pneumocystis jirovecii (Figure 4). It was therefore thought that PCP had been present on the day of his admission.

\section{Discussion}

Pneumocystis jirovecii was first described by Chagas in 1909, but it was not shown to cause human disease until 1951. In Europe, an epidemic of PCP occurred in Europe in premature and malnourished children the late 1930s and 1940s. In the 1960s and 1970s, cases of PCP were seen in patients with congenital immune defects, acquired defects secondary to malignancy or its treatment, organ transplantation, and disorders that were treated with corticosteroids or cytotoxic drugs. However, PCP remained a relatively rare condition until 1981, when AIDS was described. Since then there has been a significant increase in the incidence of PCP, which has become the most infectious complication in patients with AIDS.

The risk of PCP is increased 5-fold in in HIV patients with a CD4+ lymphocyte count of $\leq 200$ cells/ $\mu \mathrm{L}$ [7]. The other major risk factors for PCP in patients with and without HIV include-but are not limited to-a history of hematological 


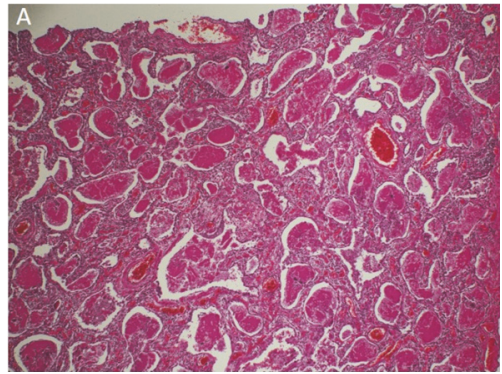

(a)

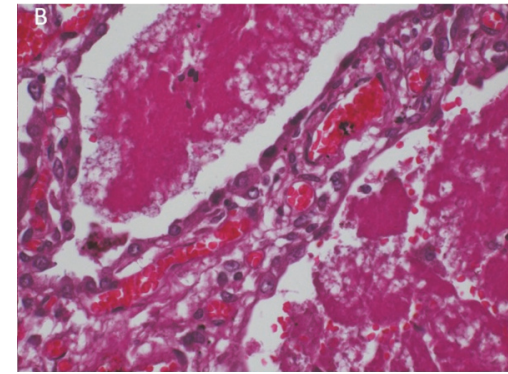

(b)

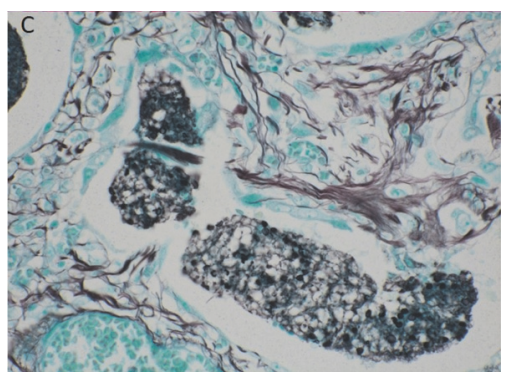

(c)

Figure 3: (a) A photomicrograph (original magnification, $\times 40$; hematoxylin-eosin staining) of a section of lung tissue. The section showed homogeneous septal thickening and intra-alveolar eosinophilic exudate. (b) A high-power photomicrograph (original magnification, $\times 400$; hematoxylin-eosin staining) of a section of lung tissue showed thickening of the alveolar septa due to both chronic inflammation and a small amount of collagen. The intra-alveolar spaces were filled with foamy acellular eosinophilic exudate. (c) A high-power photomicrograph (original magnification, $\times 400$; Grocott's methenamine silver staining) of a section of lung tissue. Numerous cysts of Pneumocystis jirovecii were observed within the intra-alveolar foamy exudate.

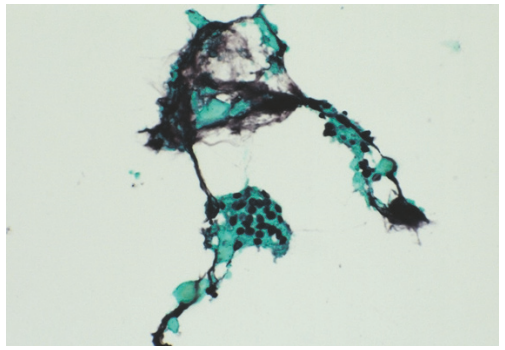

FIGURE 4: Grocott's methenamine silver staining of bronchoalveolar lavage fluid samples obtained on the day of admission revealed a small number of cystic forms of Pneumocystis jirovecii.

malignancy, organ transplantation, inflammatory conditions, solid tumors, and the use of immunosuppressive drugs. Moreover the most significant risk factors for PCP in patients without HIV are glucocorticoid use and cellmediated immunity defects, which lead to lung surfactant alterations, thereby predisposing the patient to pneumonia [8].

To the best of our knowledge, there are a few reports of PCP in patients without underlying immunosuppressive diseases (Table 1). In 1993, Cano et al. described five patients who developed PCP without any underlying conditions associated with immunosuppression; in their literature review, they only identified 11 other reported cases [3]. Since then, another three cases of PCP in immunocompetent patients have been reported [4-6]. In Cano's case series, two patients had previous or simultaneous infection by another microorganism (e.g., a viral upper respiratory tract infection or Mycoplasma pneumoniae). It was hypothesized that of PCP might develop in patients in whose immunocompetence shows a transitory alteration due to a previous or concomitant infection. In fact, Mycoplasma is reported to lead to the polyclonal activation of $B$ cells and the suppression of T cells, which would explain the appearance of transitory cutaneous anergy [9]. However, the precise mechanisms that lead to the development of PCP remain unclear.
A definitive diagnosis of PCP is made by the visualization of pneumocystis organisms on histopathological staining. The cell wall of the cysts can be visualized with GMS staining. The induction of sputum with hypertonic saline has a diagnostic yield of approximately $60 \%$ and should be performed as the initial diagnostic procedure, particularly in patients with AIDS [10]. Sputum induction may be less sensitive in patients without HIV infection because the immunodeficiency caused by HIV infection typically leads to a greater alveolar load of Pneumocystis organisms. Early fiberoptic bronchoscopy is recommended for patients in whom induced sputum is negative or from whom an induced sputum sample cannot be obtained. The diagnostic yield of BAL is $>90 \%$, and this may be increased if multiple lobes are sampled [10]. Open-lung biopsy is the most invasive procedure; however, shows very high sensitivity and specificity because it provides the greatest amount of tissue for the diagnosis [11].

We first suspected acute interstitial pneumonia based on the patient's symptoms, the physical examination findings, and the TBLB and CT findings. At first, the patient's BALF was not subjected to GMS staining (which subsequently revealed Pneumocystis jirovecii infection) because we considered that it was highly unlikely that Pneumocystis jirovecii was the causative organism based on the patient's immune status and past medical history. The high level of BG helped us to make a definitive diagnosis. BG is a cell wall component of all fungi. The serum is typically tested to determine the level of $B G$ for the diagnosis of invasive Aspergillus; however, BG is also present in the cell wall in patients with PCP.

PCP is typically associated with high levels of BG. The levels should decline with effective therapy. The potential utility of this assay was illustrated in a retrospective case-control study of 295 patients with suspected PCP. Among these subjects, BALF specimens were observed by microscopy to detect PCP and serum samples were tested for BG [12]. In that study, the BG assay had a sensitivity of $92 \%$ and a specificity of $86 \%$ for detecting PCP. In our case, the serum BG level was $104.3 \mathrm{pg} / \mathrm{ml}$ (normal, 
TABLE 1: Review of previously published cases.

\begin{tabular}{|c|c|c|c|c|c|}
\hline Author & $\begin{array}{c}\text { Patient } \\
\text { demographics }\end{array}$ & Initial presentation & $\begin{array}{l}\text { Initial radiological } \\
\text { findings }\end{array}$ & Means of diagnosis & Outcome \\
\hline \multirow{5}{*}{ Cano [3] } & 39-year-old man & $\begin{array}{l}\text { Fever and } \\
\text { dyspnea }\end{array}$ & $\begin{array}{l}\text { Left pleural effusion } \\
\text { and bilateral } \\
\text { interstitial infiltrate }\end{array}$ & $\begin{array}{l}\text { GMS staining of TNA } \\
\text { specimens }\end{array}$ & Survive \\
\hline & 30-year-old man & $\begin{array}{l}\text { Fever and } \\
\text { dyspnea }\end{array}$ & $\begin{array}{l}\text { Diffuse alveolar } \\
\text { infiltrate }\end{array}$ & $\begin{array}{l}\text { GMS staining of } \\
\text { BALF specimens }\end{array}$ & Survive \\
\hline & 37-year-old woman & $\begin{array}{l}\text { Fever, cough, and } \\
\text { malaise }\end{array}$ & $\begin{array}{l}\text { Bilateral } \\
\text { alveolointerstitial } \\
\text { infiltrate }\end{array}$ & $\begin{array}{l}\text { GMS staining of } \\
\text { BALF specimens }\end{array}$ & Survive \\
\hline & 37-year-old man & $\begin{array}{l}\text { Cough and purulent } \\
\text { sputum }\end{array}$ & $\begin{array}{c}\text { Bilateral } \\
\text { nonhomogeneous } \\
\text { alveolar infiltrate }\end{array}$ & $\begin{array}{l}\text { GMS staining of TNA } \\
\text { specimens }\end{array}$ & Survive \\
\hline & 55-year-old man & Fever and chill & $\begin{array}{l}\text { Bilateral alveolar } \\
\text { infiltrate in the } \\
\text { middle and lower } \\
\text { fields }\end{array}$ & $\begin{array}{l}\text { GMS staining of } \\
\text { BALF specimens }\end{array}$ & Survive \\
\hline Koshy [4] & 56-year-old man & $\begin{array}{l}\text { Cough, dyspnea, and } \\
\text { hemoptysis }\end{array}$ & $\begin{array}{l}\text { Bilateral } \\
\text { nonhomogenous } \\
\text { opacities in the } \\
\text { middle and lower } \\
\text { zones }\end{array}$ & $\begin{array}{l}\text { GMS staining of } \\
\text { induced sputum }\end{array}$ & Survive \\
\hline Harris [5] & 51-year-old man & None & $\begin{array}{l}\text { A right upper lung } \\
\text { nodule }\end{array}$ & Open lung biopsy & Survive \\
\hline Nejmi [6] & 30-year-old woman & $\begin{array}{l}\text { Productive cough and } \\
\text { dyspnea. }\end{array}$ & $\begin{array}{l}\text { Reticulo-micro- } \\
\text { nodular opacities in } \\
\text { the right lung }\end{array}$ & Induced sputum & Survive \\
\hline Present case & 37-year-old man & $\begin{array}{l}\text { Non-productive } \\
\text { cough }\end{array}$ & $\begin{array}{l}\text { Bilateral diffuse } \\
\text { infiltration }\end{array}$ & $\begin{array}{l}\text { GMS staining of } \\
\text { BALF specimens }\end{array}$ & Dead \\
\hline
\end{tabular}

PCP indicates Pneumocystis jirovecii pneumonia; BALF, bronchoalveolar lavage fluid; GMS, Grocott's methenamine silver; TNA, transthoracic needle aspiration; COPD, chronic obstructive pulmonary disease

$<6.0 \mathrm{pg} / \mathrm{ml}$ ); thus, we could consider PCP in the differential diagnosis and began to treat the patient accordingly. After treatment with sulfamethoxazole/trimethoprim, the value was decreased to $33.3 \mathrm{pg} / \mathrm{ml}$, nevertheless we were unable to save the patient. A serum BG assay is helpful in the differential diagnosis for PCP, and should be performed whenever high-resolution chest CT reveals diffuse bilateral ground-glass attenuation, including reticulation, septal thickening and micronodules and air space consolidation in a patient with suspected IP, because healthy individuals can develop PCP, similarly to our case.

In conclusion, we experienced a case of PCP in a patient without any underlying risk factors. It may therefore be necessary to perform a serum BG assay and GMS staining of BALF specimens in patients with diffuse ground-glass opacity, regardless of the patient's immune status.

\section{Abbreviations}

BALF: Bronchioloalveolar lavage fluid

CT: Computed tomography

GMS: Grocott's methenamine silver

PCP: Pneumocystic pneumonia

TBLB: Transbronchial lung biopsy.

\section{Data Availability}

Data have been collected retrospectively from the patient record after he deceased.

\section{Ethical Approval}

This study was approved by the Iizuka Hospital Ethical Committee.

\section{Consent}

Written informed consent was obtained from the patient's family.

\section{Conflicts of Interest}

The authors declare that they have no competing interests.

\section{Authors' Contributions}

All those named as authors have made substantial contributions to the conception and design of the study, acquisition of data, analysis and interpretation of data, drafting the article, 
or revising it critically for important intellectual content. All authors read and approved the final manuscript. All named authors have read the manuscript and have agreed to submit the paper to Case Reports in Pulmonology in its present form.

\section{References}

[1] F. J. Palella Jr., K. M. Delaney, A. C. Moorman et al., "Declining morbidity and mortality among patients with advanced human immunodeficiency virus infection," The New England Journal of Medicine, vol. 338, no. 13, pp. 853-860, 1998.

[2] J. L. Jacobs, D. M. Libby, R. A. Winters et al., "A cluster of pneumocystis carinii pneumonia in adults without predisposing illnesses," The New England Journal of Medicine, vol. 324, no. 4, pp. 246-250, 1991.

[3] S. Cano, F. Capote, A. Pereira, E. Calderon, and J. Castillo, "Pneumocystis carinii pneumonia in patients without predisposing illnesses: acute episode and follow-up of five cases," CHEST, vol. 104, no. 2, pp. 376-381, 1993.

[4] G. Koshy, J. M. Koshy, M. John, and D. Deodhar, "Pneumocystis jirovecii pneumonia in an immunocompetent host," Annals of Tropical Medicine and Public Health, vol. 8, no. 4, pp. 122-124, 2015.

[5] K. Harris, R. Maroun, M. Chalhoub, and D. Elsayegh, "Unusual presentation of pneumocystis pneumonia in an immunocompetent patient diagnosed by open lung biopsy," Heart, Lung and Circulation, vol. 21, no. 4, pp. 221-224, 2012.

[6] L. Amro, G. Hamzaoui, H. Sajiai, H. Serhane, and A. A. Yazidi, "Pneumocystis jiroveci Pneumonia in an immunocompetent female patient," Case Reports in Clinical Medicine, 2014.

[7] W. T. Hughes, "Natural mode of acquisition for de novo infection with pneumocystis carinii," The Journal of Infectious Diseases, vol. 145, no. 6, pp. 842-848, 1982.

[8] M. Chabé, E. Dei-Cas, C. Creusy et al., "Immunocompetent hosts as a reservoir of Pneumocystis organisms: Histological and RT-PCR data demonstrate active replication," European Journal of Clinical Microbiology \& Infectious Diseases, vol. 23, no. 2, pp. 89-97, 2004.

[9] G. H. Cassell and B. C. Cole, "Mycoplasmas as agents of human disease," The New England Journal of Medicine, vol. 304, no. 2, pp. 80-89, 1981.

[10] M. Cruciani, P. Marcati, M. Malena, O. Bosco, G. Serpelloni, and C. Mengoli, "Meta-analysis of diagnostic procedures for Pneumocystis carinii pneumonia in HIV-1-infected patients," European Respiratory Journal, vol. 20, no. 4, pp. 982-989, 2002.

[11] L. L. Michaelis, G. S. Leight Jr., R. D. Powell Jr., and V. T. DeVita, "Pneumocystis pneumonia: The importance of early open lung biopsy," Annals of Surgery, vol. 183, no. 3, pp. 301-306, 1976.

[12] S. Tasaka, N. Hasegawa, S. Kobayashi et al., "Serum indicators for the diagnosis of pneumocystis pneumonia," CHEST, vol. 131, no. 4, pp. 1173-1180, 2007. 


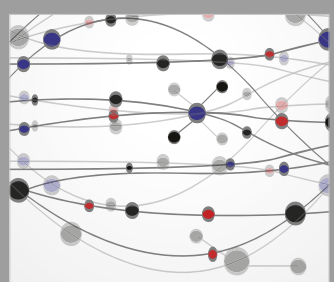

The Scientific World Journal
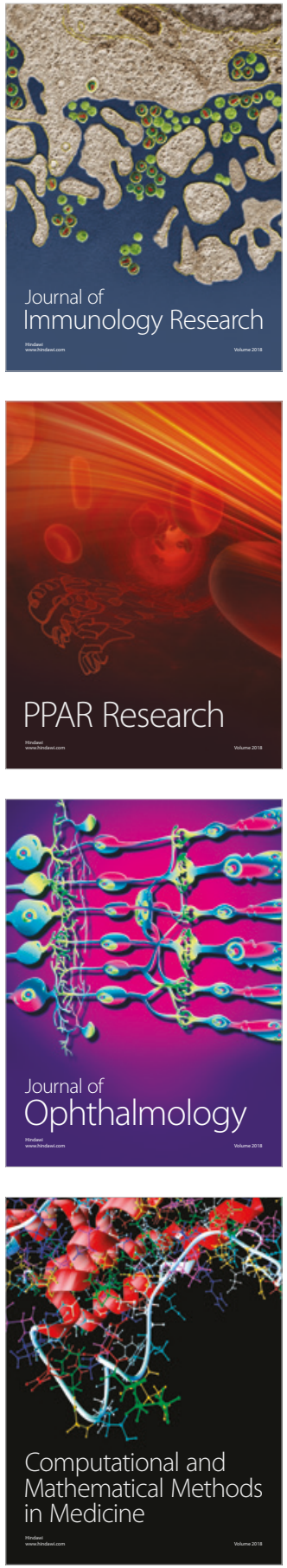

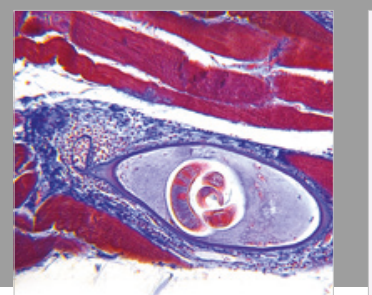

Gastroenterology Research and Practice

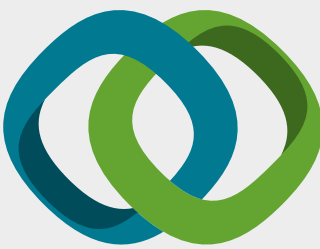

\section{Hindawi}

Submit your manuscripts at

www.hindawi.com
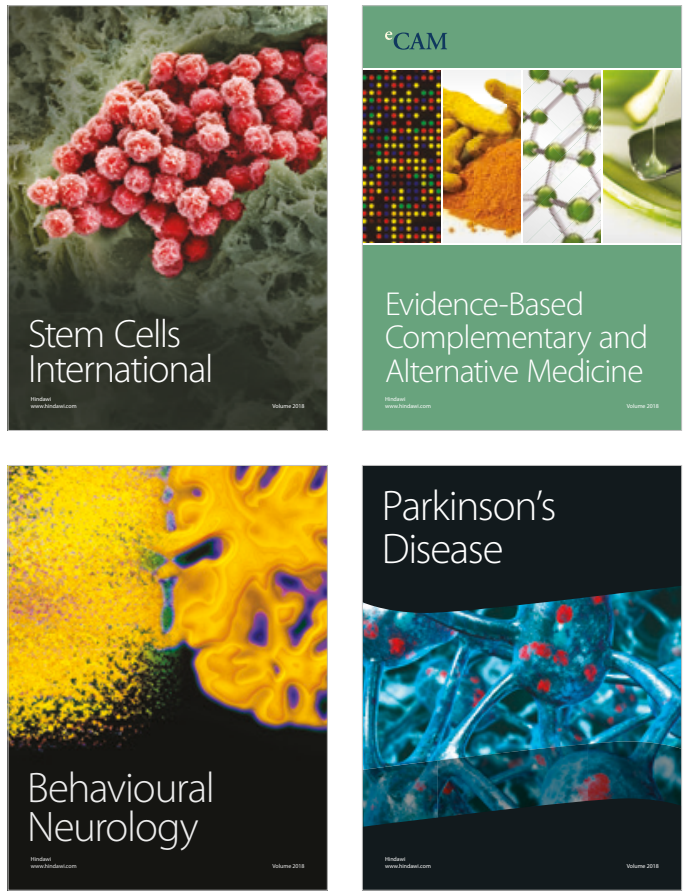

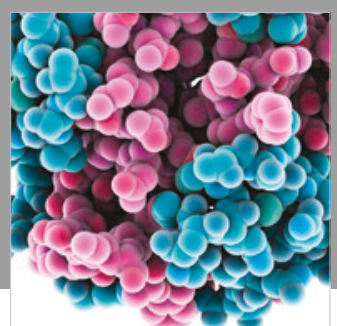

ournal of

Diabetes Research

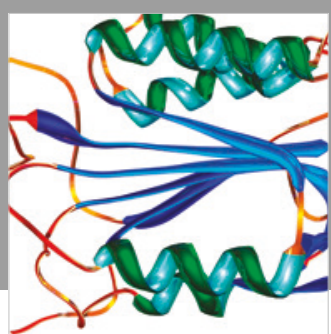

Disease Markers
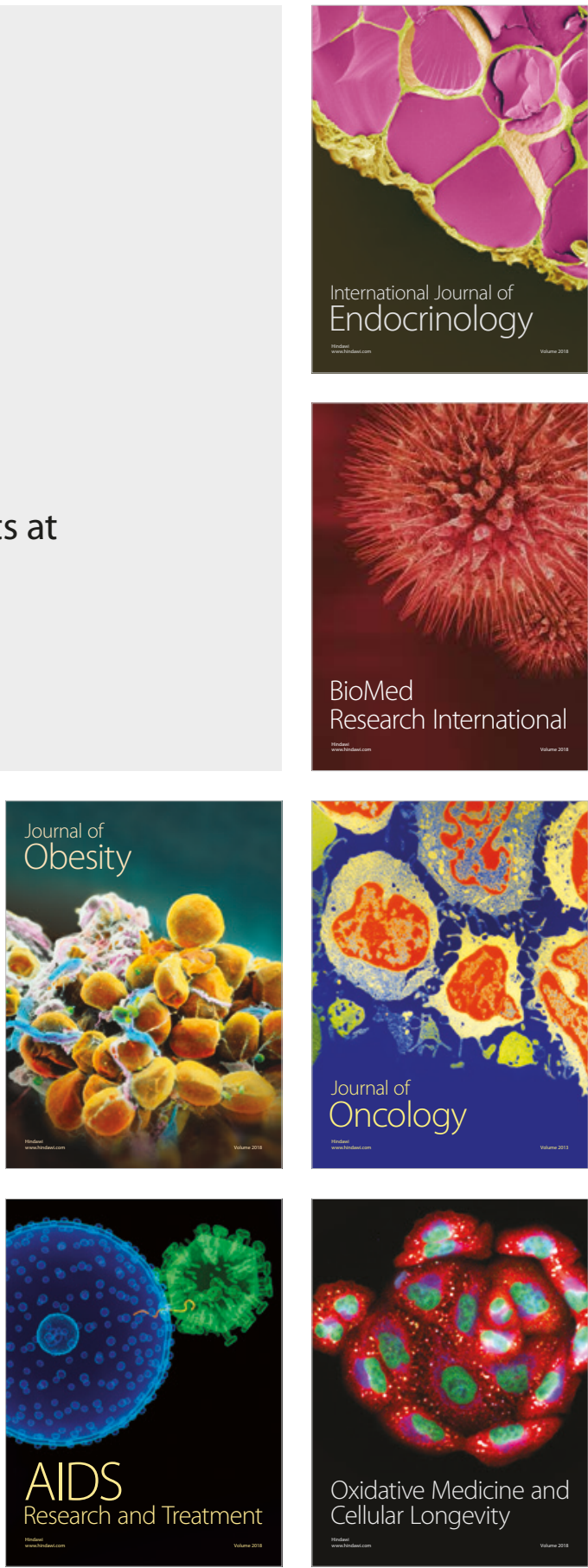